\title{
Sobre la lectura rortyana de la obra de Michel Foucault ${ }^{1}$
}

\author{
About Rorty's reading of Michel Foucault's work \\ JOAQUÍN FORTANET \\ Universidad de Barcelona
}

Recibido: 22-10-2007 Aprobado definitivamente: 07-11-2007

RESUMEN

Este texto plantea un seguimiento pormenorizado de la interpretación que Richard Rorty realiza de la obra de Michel Foucault. Dicha lectura es primordial a la hora de establecer un Foucault con dos rostros: uno americano y otro francés. Dicha división permite realizar una lectura en clave liberal de la obra de Foucault, abriendo así la posibilidad, en la filosofía de Rorty, para utilizar la filosofía post-nietzshcheana como instrumento adecuado al neo-pragmatismo.

PALABRAS CLAVE

FOUCAULT, RORTY, CRÍTICA, PODER, NEO-LIBERALISMO

\begin{abstract}
This paper proposes a detailed study of Richard Rorty's reading of the work of Michel Foucault. Such interpretation is of paramount importance to create a two-faced Foucault: one of them American, and the other one French. This division enables us to carry out a liberal reading of Foucault's work, allowing (according to Rorty's thought) the use of post-Nietzschean philosophy as an appropriate tool for Neopragmatism.
\end{abstract}

\section{KEY WORDS}

FOUCAULT, RORTY, CRITICISM, POWER, NEO-LIBERALISM

1 Trabajo realizado con el apoyo de la Universidad de Barcelona, el Seminario de Filosofía Política de la misma y el Insitut Mémoires de l'Edition Contemporaine (IMEC), de París.

(C) Contrastes. Revista Internacional de Filosofía, vol. XIV (2009), pp. 99-117. ISSN: 1136-4076

Licenciatura de Filosofía, Universidad de Málaga, Facultad de Filosofía y Letras Campus de Teatinos, E-29071 Málaga (España) 
Nunca hubo un debate Real entre Foucault y Rorty. Sus encuentros fueron más bien tangenciales y pueden perfectamente datarse. El primero, a instancias de P. Rabinow, tuvo lugar en Junio de $1981,{ }^{2}$ en Paris, como resultado de una conferencia previa de Foucault en Princeton en noviembre de 1980. En dicha conferencia, titulada The Origin of Biopower, ${ }^{3}$ Rorty escuchó con interés las ideas foucaultianas sobre el cuidado de sí como práctica de la libertad. Sin duda, dicho concepto guardaba una estrecha relación con la idea de creación de sí y, como veremos, para Rorty constituye uno de las grandes aportaciones de la filosofía foucaultiana a la perfección privada. Tras dicho encuentro, la relación entre Rorty y Foucault se afianzó en la medida en que Foucault acogió con relativo entusiasmo la lectura, en 1981, del primer gran libro de Rorty, La filosofía y el espejo de la naturaleza. Tras dicha lectura, Foucault recomendó su publicación a la editorial francesa Seuil, afirmando que dicha lectura animaría a los jóvenes franceses a ser «menos entusiastas con la filosofía analítica». ${ }^{4} \mathrm{La}$ aceptación, pues, de la primera obra rortyana fue positiva por parte de Foucault. Sin embargo, dicho entusiasmo bajó de intensidad hasta convertirse, en 1983, en una prevención hacia el modo en que Rorty comenzaba a utilizar ciertos conceptos foucaultianos. Por su parte, la fascinación de Rorty por Foucault nunca dejó de crecer. Pese a que los ataques a sus implicaciones políticas fueron, en ocasiones, durísimos, Rorty siempre mantuvo -excepto en una ocasión que ya trataremos convenientemente- un alto respeto por el valor intelectual de Foucault, llegando, al final de su vida, a preocuparse notablemente por el hecho de permanecer vinculado a la línea foucaultiana de un pensamiento liberador, creador, productor de libertad más que a la tradición puramente liberal y consuetudinaria. ${ }^{5}$

Aunque, la obra de Rorty se encuentre plagada de referencias constantes a la filosofía foucaultiana, a la hora de reconstruir el cuerpo de la interpretación rortyana de Foucault es necesario atenerse a los principales textos que desarrollan, no referencias puntuales, sino interpretaciones de fondo acerca de temas cruciales. Es por ello por lo que se manejarán una selección reducida de textos, en concreto cinco textos que construyen la perspectiva completa de la labor interpretativa y la problemática de Rorty con respecto a Foucault. En

2 Carta de Rorty a Foucault, 28 Abril de 1981, Archivo del Institut Mémoires de l'Edition Contemporaine (IMEC), Paris.

3 Carta de Rorty a Foucault, 3 de Diciembre de 1980, Archivo del IMEC, Paris.

4 Comunicación personal de Rorty, 28 Junio del 2006.

$5 \quad$ Ibid. Sin duda, fruto de la preocupación rortyana por el hecho de que en Europa se destacaba su filiación al liberalismo conservador más que a las propuestas liberadoras de la 'izquierda' filosófica. Hasta tal punto que una de sus preocupaciones últimas fue la de encontrar documentos que certificasen con precisión el papel de Foucault en la traducción al francés de sus obras hasta 1984. 
primer lugar, el conocido texto, de obligada referencia, Identidad moral y autonomía privada. ${ }^{6}$ En segundo lugar, Dewey versus Foucault. ${ }^{7}$ En tercer lugar, Foucault et l'épistémologie. ${ }^{8}$ En cuarto, Beyond Nietzsche and Marx. ${ }^{9} \mathrm{Y}$, por último, un texto poco conocido y revelador: Paroxysms and politics. ${ }^{10} \mathrm{~A}$ través de estos cinco textos es posible armar la interpretación de la labor foucaultiana en el seno del pensamiento de Rorty que nos provea con las claves del debate inexistente que pretendemos construir. Una de las piezas clave del debate es la conferencia realizada por Rorty en el coloquio organizado en 1988 en París por el Centre Michel Foucault, titulada Identidad moral y autonomía privada. ${ }^{11}$ En dicha conferencia, Rorty lee a Foucault a través de tres ejes fundamentales: la concepción de poder, la dicotomía público-privado y el concepto ético de evitar el sufrimiento. Es decir, la lectura de Foucault pasará por una crítica filosófica (al concepto de poder), política (a la ausencia de división públicoprivado) y ética (no asunción de la ética del no sufrimiento). En cuanto a la crítica filosófica, Rorty separa, asumiendo una división de V. Descombes, ${ }^{12}$ dos rostros distintos de Foucault debidos a los intentos por apropiarse de su obra. Un rostro norteamericano y un rostro francés. ${ }^{13} \mathrm{El}$ rostro norteamericano, influenciado por la labor pedagógica con la que Foucault trató de introducir en Estados Unidos sus reflexiones sobre la antigua Grecia y el cuidado de sí, nos presenta a un Foucault desvinculado de las tormentas políticas francesas, de su nietzscheanismo, preocupado por encontrar una suerte de ámbito de creación de la propia vida que, según Rorty, puede ser asimilado a la labor pragmatista de Dewey. Por otro lado, el rostro francés de Foucault es el rostro auténticamente nietzscheano, sumido en la reflexión teórica y práctica sobre el poder, imbuido en la lucha por la resistencia. En definitiva, un Foucault liberal y un Foucault antiliberal dependiendo del grado de nietzscheanismo que asuma su rostro y que es la encarnación la de la tensión característica del «intelectual romántico

6 R. Rorty, Heidegger y otros pensadores contemporáneos, Barcelona: Paidós, 1993, pp. 269 y ss.

7 R. Rorty, Consecuencias del pragmatismo, Madrid: Tecnos, 1996, pp. 288 y ss.

8 R. Rorty, «Foucault et l'épistémologie», en D.Couzens (ed), Foucault: lectures critiques, Bruselas: Ed. DeBeck, 1989, pp. 55 y ss.

9 R. Rorty, «Beyond Nietzsche and Marx», en London Review of Books, London, 1981, vol.3, pp. 5-6

10 R .Rorty, «Paroxysms and politics», en R. Boyers (ed.), The new Salmagundi Reader, Syracuse: Syracuse University Press, 1996, pp. 513 y ss.

11 R. Rorty, Heidegger y otros pensadores contemporáneos, op. cit., pp. 269 y ss.

12 V. Descombes, «Revision de Foucault: A critical reader», en London Review of Books, London, 1987, p.3

13 R. Rorty, op. cit., p. 269 
que también es ciudadano de una sociedad democrática». ${ }^{14}$ Ciertamente, existen motivos para pensar con Descombes y Rorty que el llamado Foucault americano posee un carácter distinto al Foucault francés. De hecho, la introducción por parte de R. Dreyfuss y, sobre todo, Paul Rabinow de Foucault en la universidad americana ${ }^{15}$ supuso para su trabajo una suerte de paréntesis, de tabula rasa, de empezar, de nuevo, a componer una obra que quizás precisaba perder cierto lastre cultural francés para poder conformarse como una nueva reflexión acerca de las prácticas de sí. ${ }^{16}$ Esta frescura, que se debía a un nuevo auditorio de distinto patrón cultural, llevó a la interpretación americana de Foucault que Rorty intenta acercar al pragmatismo de Dewey. Para Rorty, el Foucault americano se ha librado del nietzscheanismo que le impedía ejercer de ciudadano de una liberal-democracia. Su preocupación por el cuidado de sí le acerca al intelectual romántico que, pese a estar preocupado por la propia autocreación, no intenta que dicha autocreación devenga una máxima moral y política para la comunidad entera, al contrario que ocurría con el rostro nietzscheano de Foucault. Sin embargo, Rorty lamenta que, incluso privado del nietzscheanismo romántico, Foucault nunca adopte el vocabulario de la comunidad, que intente «ayudar a la gente sin tomar el vocabulario de ésta como el vocabulario en que él se habló a sí mismo [...] inventando, al mismo tiempo, un sí mismo que no tenía mucho que ver (o mejor dicho lo menos posible) con el de los demás». ${ }^{17}$ La no adopción de tal vocabulario responde a uno de los núcleos nietzscheanos que no pueden ser separados de la labor foucaultiana: la sospecha de la verdad, la sospecha del territorio neutral del lenguaje común, del saber, las implicaciones y redes que unen, tejiendo, el entramado entre el saber y poder. Justamente, el motivo de la no adopción del lenguaje de la comunidad, es, según Rorty, el motivo de discordia entre Foucault y Dewey:

Al reflexionar sobre las ciencias sociales, Foucault no veía un territorio neutral entre el concepto clásico, galileano, de ciencia conductista y el concepto francés de sciences de l'homme. En este territorio neutral residía precisamente la propuesta de Dewey [...]. Dewey nos proponía seguir siendo fieles a esa voluntad de verdad y al optimismo que ésta implica [...] pues en manos de Dewey la voluntad de verdad no es el deseo de dominar, sino de crear. ${ }^{18}$

14 Ibid., p. 269

15 Particularmente, en California y Berkeley. A partir de 1977 aparecieron numerosas antologías de su obra en Estados Unidos.

16 El mismo Foucault, identificaba Estados Unidos como una especie de liberación tanto teórica como práctica y personal. Ver al respecto, E. Fassin, «Résistances de Foucault», en D. Eribon (ed.), L'infréquentable Michel Foucault, Paris: EPEL, 2001, pp. 175 y ss.

17 R. Rorty, op. cit., p. 273

18 R. Rorty, Consecuencias del pragmatismo, op. cit., p. 293. 
Así pues, existen en la lectura rortyana dos niveles de nietzscheanismo en Foucault que nos ofrecen un rostro americano y un rostro francés de Foucault. Un rostro americano que podemos acercar, con salvedades, a Dewey y al pragmatismo y un rostro francés que, presa del nietzscheanismo más enraizado, debemos rechazar. El rechazo al nietzscheanismo francés se nos presenta como una crítica filosófica al concepto de poder. Dicho concepto, según Rorty, adolece de una ambigüedad fundamental que responde a dos usos distintos del concepto. El primero, más restringido, se refiere a un uso peyorativo del concepto. Es decir, según Rorty dicho uso de poder correspondería al análisis de las formas en que el poder -interpretado peyorativamente- no deja aflorar las cuestiones de la verdad y la libertad. En este sentido, este poder peyorativo, de corte represivo, nos ofrecería un campo de análisis válido para la democracia liberal y el pragmatismo. Sin embargo, Foucault, en su reflexión sobre el poder, entiende que existe un uso productor del término poder. Un uso del que se deriva que cualquier construcción social, cualquier relación humana es un precipitado de relaciones de poder. En este sentido, según Rorty, dicho uso de poder entroncaría con la tradición de la voluntad de poder nietzscheana, es decir, con un uso trascendental, neutral y vacío del mismo.

Foucault nos permitió cobrar conciencia de un conjunto de peligros nuevos que amenazan a las sociedades democráticas. Prestó buenos servicios a esas sociedades al indicarles las tendencias y los esquemas que debían vigilar [...]. Pero, por otro lado, nosotros, liberales reformadores, pensamos que el trabajo de Foucault está penetrado por la ambigüedad representada por dos acepciones de la palabra «poder» [...] nosotros los reformistas liberales pensamos que la obra de Foucault está dominada por una lastrante ambigüedad entre «poder» como término peyorativo y como término neutral y descriptivo. ${ }^{19}$

Vemos, pues, que, para Foucault, la neutralidad de la voluntad de verdad deweyana que se expresaba en el territorio neutral del lenguaje común es extrapolada hacia la neutralidad de las relaciones de poder. De este modo, la sospecha de todo territorio por ausencia de neutralidad se hace coextensivo a toda su filosofía. El único territorio neutral es, precisamente, el territorio a combatir, las relaciones de poder. Esta negativa, pues, a « hacerse cómplice del poder ${ }^{20}$ es la que le llevó, según Rorty, a un semi-anarquismo que sospecha de todo y que impide constituirse como un ciudadano de una democracia liberal. Y que le coloca en la peor disposición posible, filosóficamente hablando, para un ironista liberal: más allá de Nietzsche y Marx, entendiendo dicho «más allá» 
como una prolongación de la radicalidad de sus tareas. Pese a que el núcleo nietzscheano del pensamiento de Foucault no pueda aceptar un marxismo ortodoxo que se considera a sí mismo como una ciencia, o como un materialismo histórico racional, la genealogía foucaultiana puede leerse como un intento de realizar una historia crítica del presente que, en su crítica, adopta numerosos elementos marxistas tales como la lucha de clases, la concepción de la crítica, la producción -no tan sólo económica- como clave de alienación, la disciplina del trabajo como un modo de producción de un sujeto trabajador. Es así como Rorty vincula la crítica a las instituciones liberales y al mercado ${ }^{21}$ con la estela de Marx. Aunque Foucault, ontológica y epistemológicamente no acepte la estela de Hegel y Marx y adopte la de Nietzsche, Rorty ve en su análisis de las instituciones liberales posiciones cercanas a la denuncia de los aparatos ideológicos, de las luchas de clases, de las disciplinas que constituían a un hombre a base de miseria y explotación, un hombre que debía dejar de ser él mismo para poder liberarse.

Foucault pretende una genealogía, una historia del presente que dé cuenta de porqué damos por sentado aquello que creemos obvio [...]. Este tipo de genealogía podría entenderse como parte de una historia marxista en el sentido en que desacreditaría las instituciones contemporáneas liberales [...]. El movimiento de Foucault más allá de Marx y Nietzsche es una brillante iniciativa de un filósofo de primer orden. ${ }^{22}$

Así, la obra de Foucault realizaría un movimiento que liga con el marxismo en su crítica política y que mantiene una profunda inspiración nietzscheana tanto en la idea de un poder productor como en la ligazón entre la voluntad de verdad y el poder. Ahora bien, la pregunta que nos surge es la de porqué una parte de la crítica de Rorty a Foucault pasa por la cuestión de la verdad. Cuestión que, a la postre, parecía unir a ambos pensadores en su vertiente anti-epistemológica. Sabemos que Foucault no acepta el marxismo debido, principalmente, al poso de verdad y objetividad que éste arrastra en nociones como ideología, sujeto político, dialéctica e historia. Y podemos presumir que el rechazo rortyano al marxismo se podría situar en una línea parecida, la de la denuncia de su voluntad de verdad. Sin embargo, la adecuación entre la anti-epistemología rortyana y la epistemología foucaultiana no es una cuestión que pueda tratarse fácilmente. Recordemos que una de las máximas nietzscheanas que incorpora Foucault es la de abandonar la voluntad de verdad. En cambio, la anti-epistemología rortyana aboga, más bien, por abandonar toda verdad que se quiera separar de su justificación. Para Rorty la verdad es una verdad social, una construcción 
compartida que, en lo público, presenta rasgos de una cierta espesura necesaria para la constitución de la solidaridad. La construcción del nosotros precisa un suelo común, un vocabulario compartido en el que no existe la ironía pública, sino redescripciones orientadas a convencer a la comunidad sobre la adopción de una nueva verdad que resulta más útil a la constitución de ese nosotros. Se podría decir que la raíz filosófica rortyana, en la medida en que procede de Dewey, comparte con el hegelianismo la voluntad de realizar una redescripción histórica de las verdades racionales:

El hegeliano alaba la superioridad de nuestra cultura sobre el pasado, en lugar de alabar su reflejo fiel de una realidad ahistórica. No observa en las ciencias exactas más objetividad que en las imprecisiones, no contempla ningún secreto metodológico garante del éxito [...]. Ríe ante la idea de que el conocimiento tenga una naturaleza que deba ser estudiada por una disciplina filosófica. ${ }^{23}$

Para Rorty, las variantes del hegelianismo como la deweyana se oponen al cartesianismo por su historicismo y, en la estela de dicho historicismo orientado a conceder la primacía del presente sobre el pasado y la verdad como una justificación social que progresa no mediante correspondencia sino mediante sucesivas redescripciones útiles para la comunidad, la voluntad de verdad no se debe abandonar, sino abrir a la historia, a la redescripción y, en fin, a la utilidad social. Es por ello por lo que Rorty, junto a toda una serie de pensadores de corte pragmatista, concibe el hegelianismo como una reacción al cartesianismo y a su imagen de la mente como espejo de la naturaleza. Desde esta perspectiva, bien pueden interpretarse las reacciones contra la representación como parte del impulsó historicista que, desde Hegel hasta Dewey, buscó dilapidar la confianza en los universales ahistóricos. ${ }^{24}$ De este modo, a la hora de buscar un Foucault americano, el pragmatismo tiende a realizar una lectura hegeliana de Foucault, a vincular sus últimas teorías sobre el cuidado de sí con una anti-epistemología historicista de corte hegeliano. Sin embargo, el mismo Rorty hace notar la imposibilidad de tal acercamiento. La filosofía continental, especialmente la post-nietzscheana, ha identificado al cartesianismo y al hegelianismo como síntomas del mismo impulso metafísico, y la reacción contra dicho impulso viene representada como la asunción del impulso nietzscheano. Es Nietzsche, pues, el elemento que impide una lectura hegeliana de Foucault, una concepción historicista de la voluntad de verdad. Es la epistemología nietzscheana la que aleja la concepción de la verdad foucaultiana de la rortyana. 
La posición de Foucault en relación a la epistemología es nietzscheana: no hay, según él, nada optimista a afirmar. Poner en cuestión, como Nietzsche, la voluntad de verdad es rechazar el impulso común a la epistemología cartesiana y la historiografía escatológica hegeliana. El nietzscheano quiere abandonar la búsqueda de la objetividad y la intuición de la unicidad de la Verdad, no redescribirla o justificarla. $^{25}$

Negando, pues, la voluntad de verdad, negando el representacionismo y el historicismo, el nietzscheanismo epistemológico de Foucault impide no sólo cualquier intento de redescripción de la voluntad de verdad orientado a conceder el valor de justificación social a una creencia, sino que dinamita la concepción del progreso histórico, sospechando de toda teoría que se ampare en el pasado. La historia, tal y como vimos, no es más que una serie de rupturas, de discontinuidades, de acontecimientos que resultan inconmensurables en la medida en que no existe una red teleológica que nos sirva de elemento inteligible. Introducir en la raíz misma del pensamiento la noción de discontinuidad, de acontecimiento, de materialidad y de azar es el objetivo de la genealogía, alternativa al historicismo que impide el acercamiento a la noción de verdad como justificación rortyana y lleva al abandono de tal noción. Así, una vez abandonado, vía nietzscheana, la noción de verdad y de voluntad de verdad, la genealogía se enfrenta con la noción de poder. Si la verdad no posee un espesor ontológico propio, las verdades del presente no son más que producciones del poder. Negación, pues, del progreso, negación del desarrollo histórico como práctica de la libertad o la razón, negación de la verdad misma. Sin embargo, según Rorty, aquí vuelve a aparecer el elemento de poder como un trascendental que sustituye a la noción de voluntad de verdad. Sustituir la voluntad de verdad por la voluntad de poder no nos ofrece alternativas útiles. Si Foucault no hubiese renunciado totalmente a esa voluntad de verdad, si hubiese aceptado el hecho de que es posible contar con las nociones de progreso, de maduración y de síntesis «admitir que únicamente conocemos al mundo y a nosotros mismos en función de una descripción [...] sería admitir que, si hemos llegado a tal descripción, quizás sea por azar». ${ }^{26}$

Con ello, la renuncia total a la voluntad de verdad mantiene una estrecha relación, según Rorty, con la adopción de una noción de poder trascendental, vacía, omniabarcadora. La adopción de un poder puramente peyorativo, no productivo, permitiría realizar una lectura de Foucault plenamente americana, como corrector de los excesos filosóficos del hegelianismo y los excesos prácticos del sistema democrático liberal. En este sentido, sería posible, desde la 
perspectiva rortyana, la participación de Foucault en la vida pública. Es decir, Rorty aboga por la posibilidad de separar el poder del saber en la epistemología foucaultiana, deteniéndola en el momento en el que no ha cumplido el movimiento nietzscheano completo y sólo ha denunciado al cartesianismo y al hegelianismo sustituyéndolos por la discontinuidad histórica, por el acontecimiento. Si se detuviera aquí su epistemología, podría pensarse la aceptación de la redescripción como modo de asumir la discontinuidad, aceptando así no la verdad sino la voluntad de verdad como elemento contingente al que, en tanto comunidad, estamos ligados. La operación rortyana pasa por introducir un sesgo entre dos supuestos conceptos de poder en la obra de foucault. Uno, peyorativo, que sería aceptado en tanto puede ayudar a corregir los excesos filosóficos y prácticos. Otro, productor, que es desestimado por trascendental y vacío. Si se asume dicha distinción y se expulsa la raíz nietzscheana del poder como campo de batalla, de las relaciones de poder como precipitados de relaciones humanas, de relaciones de saber y de prácticas sociales, entonces, es posible leer a Foucault como una suerte de sociólogo, ${ }^{27}$ como un compañero de viaje de las aspiraciones de Dewey. Una vez el poder productor es rechazado, el poder es considerado de un modo peyorativo, y la tarea pasa a ser limitar sus excesos. Sin embargo, este poder peyorativo no es puramente represivo, ya que forma parte del entramado cultural al que pertenecemos. Así, el poder peyorativo se acercaría a la concepción instrumental de cultura de Dewey, es decir, como un entramado cultural e instrumental. Dicho entramado contiene elementos negativos, que entroncarían con la concepción peyorativa foucaultiana en tanto excesos, pero, al mismo tiempo, forman nuestro suelo a partir del cual podemos desarrollar un progreso basado en la redescripción de nuestra tradición. Forman nuestra cultura: «Una vez que el poder deja de connotar represión, las estructuras de poder de las que habla Foucault no nos parecerán muy distintas de las estructuras de cultura de las que habla Dewey». ${ }^{28}$

Sustituyendo «poder» por «cultura», Rorty plantea la posibilidad de que, en la lectura americana de Foucault, sus análisis sirvan a la comunidad liberal, le sean útiles para denunciar sus excesos y permitan, al mismo tiempo, concebir dicha comunidad como una progresiva realización de la solidaridad y la libertad. Es así como construcciones del poder denunciadas por Foucault ahora son parte de nuestra cultura, y como tales forman parte de nuestra comunidad. Carece de sentido, para Rorty, la denuncia íntegra de nuestra tradición. Más bien su mejora, su reforma mediante la redescripción es el camino más útil: «pienso que la sociedad liberal contemporánea ya incluye las instituciones necesarias para alcanzar su propia mejora: una mejora que puede mitigar los peligros que

27 Ibid., p. 241.

28 R. Rorty, Consecuencias del pragmatismo, op. cit., p. 295. 
Foucault ve». ${ }^{29}$ En este sentido, Rorty ve en la figura de Dewey un reformador que concibió las ideas más útiles de Foucault y que, al mismo tiempo, posibilitó una reflexión política optimista, útil a los intereses de la democracia liberal. ${ }^{30}$ Y es aquí donde Rorty introduce la crítica política a Foucault, a partir de la crítica filosófica al poder. Al asumir la raíz nietzscheana hasta el final, Foucault no puede distinguir su moral en cuanto ciudadano y su búsqueda de autonomía personal, ya que el poder como trascendental le obliga a rechazar cualquier colaboración con el mismo y colaborar con el poder cuando éste lo envuelve todo, significa adoptar un vocabulario común, participar como ciudadano, aceptar una voluntad de verdad aunque ésta sea pura redescripción de la tradición. Así, la crítica política viene del hecho de que Foucault, con su nietzscheanismo, invade el territorio de lo público con sus sueños de autonomía privada:

Yo hubiera deseado que Foucault se inclinara más a distinguir estos dos papeles, a distinguir su identidad moral de ciudadano y su busca de autonomía personal. Entonces habría podido resistir la tentación a la que sucumbieron Nietzsche y Heidegger: la tentación de buscar en su propia esfera privada una contrapartida pública y política. Fue esa tentación la que provocó su casi anarquismo y su negativa a ser cómplice del poder. ${ }^{31}$

De este modo, Rorty identifica al Foucault anarquista con el Foucault nietzscheano, esto es, francés, y al Foucault más sosegado, posible heredero de la ilustración y abierto a la posibilidad de cimentar un suelo común en la redescripción de la comunidad, con el Foucault americano. ${ }^{32}$ Hemos observado qué es lo que aleja, para Rorty, al Foucault americano del francés en relación al aspecto filosófico: el nietzscheanismo, asumido parcialmente en la lectura norteamericana mediante la separación entre los dos tipos de poder, identificando, en el límite, la noción de poder con la de cultura y asumiendo, de este modo, la posibilidad de una redescripción social como progreso. Ahora, la

29 R. Rorty, Contingencia, Ironía y Solidaridad, Barcelona: Paidós, 1996, p. 82.

30 Sobre las relaciones entre Dewey y Foucault, ver F. J. Macke, «Pragmatism reconsidered», en L. Langsdorf (ed.), Recovering Pragmatism's Voice, New York: University of New York Press, 1995, pp. 164 y ss. En dicho texto, F. J. Macke realiza una equiparación entre el concepto de experiencia foucaltiano y el deweyano. Sin embargo, creemos que tal comparación no es exacta dado que el concepto de experiencia de Foucault y el de Dewey parten de concepciones del lenguaje inconmensurables. La experiencia de Dewey forma parte de una concepción instrumental de la cultura en la que el sujeto asume sus experiencias primarias para contextualizarlas en el marco de la investigación, mientras que, para Foucault, la experiencia tiene como modelo el lingüístico y es, fundamentalmente, política.

31 R. Rorty, op. cit., p. 326.

32 R. Rorty, Heidegger y otros pensadores contemporáneos, op. cit., p. 271. 
tarea es analizar aquello que, para Rorty, aleja políticamente al Foucault americano del francés. La diferencia se hace explícita desde el momento en que se identifica al Foucault americano con una suerte de liberal posmoderno, y al Foucault francés como un anarquista posmoderno. En cuanto al liberalismo del Foucault americano, Rorty afirma que se trata de un modo de hacer política que se colige de sus posiciones orientadas a desembarazarnos de la sobrecarga universalista que conforma los metarrelatos que nos oprimen. Una buena parte de la reflexión sobre el bio-poder podría apoyar esta interpretación, en la medida en que el poder sobre la vida no es más que una sobrecarga de intervención sobre el propio discurrir natural de la existencia. ${ }^{33}$ De este modo, contra la sobrecarga del poder y del biopoder, este Foucault americano, según Rorty, estaría dispuesto a conceder la validez de una política liberal sin presupuestos metafísicos o epistemológicos:

Este Foucault nos dice que las democracias liberales podrían funcionar mejor si dejasen de intentar ofrecer autojustificaciones universalistas, si dejasen de apelar a nociones como racionalidad y naturaleza humana y en su lugar se considerasen a sí mismas simplemente como experimentos sociales prometedores. ${ }^{34}$

Por otra parte, en la visión americana, la política de Foucault es identificada con parte de las últimas luchas libradas a favor de la comunidad homosexual, particularmente centradas en sus intervenciones en California. Debido a la confluencia de diversos factores sociales y políticos, ${ }^{35}$ la utilidad política de Foucault se circunscribe a la lucha política por el reconocimiento de la comunidad homosexua ${ }^{36}$ ligada a la reivindicación de una existencia plena, creadora de sí, fuertemente individualista. Así, D. Halperin, en los años 90, afirma taxativamente que era la obra teórica de Foucault la que estaba detrás de la mayoría de movimientos de liberación homosexual y de lucha contra el sida, como Act Up New York. ${ }^{37}$ El mismo Rorty coincide en señalar que el mayor -y único- logro

33 De hecho, no es casual que uno de sus más aventajados discípulos, F. Ewald que publicó una dura crítica al Estado de bienestar (F. Ewald, L'état providénce, Paris: Bernard Grasset, 1986) haya encontrado en la democracia liberal el marco político para resistir a la sobrecarga de intervención sobre la propia vida, llegando a afirmar que concesiones políticas intervencionistas como el derecho al subsidio de desempleo suponen una intervención ilegítima del poder estatal sobre el desarrollo de la propia vida.

34 Ibid., p. 269.

35 E. Fassin señala los principales: la era Reagan, el anti-intelectualismo de la izquierda liberal norteamericana y el alejamiento de los intelectuales de la sociedad. Ver al respecto, E. Fassin, op. cit., pp. 177 y 178.

36 Y, posteriormente, feminista. Ibid., pg. 180.

37 D. Halperlin, Saint Foucault, Paris: EPEL, 2000. 
político de Foucault, además de mostrar los excesos del sistema político, fue el de proporcionar marcas liberadoras políticas a la comunidad homosexual:

Foucault ha sido muy valioso a la hora de cambiar actitudes culturales hacia la homosexualidad, pero no estoy muy seguro de si ha tenido gran repercusión en otras áreas. Surveiller et punir no aportaba ninguna sugerencia de cambio en el sistema criminológico judicial, y es difícil de imaginar cómo podría ser puesto en práctica. Foucault fue un hombre brillante, pero su brillantez fue utilizada para arrojar sospecha sobre las instituciones más que para intentar reformarlas. ${ }^{38}$

Ahora bien, si la participación política de Foucault ha sido notablemente mayor en temas como la prisión o el encierro psiquiátrico, ¿por qué el Foucault americano es presentado únicamente como un filósofo queer, «santo patrón de los gais» -en expresión de D. Halperlin-, en definitiva, como un pensador cuya política conduce única y necesariamente a esta lucha concreta? La respuesta, es triple. Por un lado, factores sociales y culturales posibilitaron que la obra de Foucault cuajara en esta lucha política concreta, dando armas, motivos y dirección al movimiento homosexual, queer y feminista estadounidense. Sin embargo, hay otra respuesta posible, complementaria. Si comparamos el movimiento feminista francés con el movimiento queer norteamericano, lo que encontramos es una disimetría en torno al concepto de poder ${ }^{39}$ Un concepto de poder, leído al modo americano, que hace hincapié en la resistencia restando énfasis al poder como productor, como hilo que traza las relaciones culturales. En el límite, un poder considerado peyorativamente, del mismo modo en que Rorty nos habla de un poder que puede contribuir a la mejora de la sociedad. Es, pues, este aspecto del pensamiento de Foucault, sin duda un aspecto positivo u optimista, el que se privilegia en la lectura estadounidense. Aspecto positivo, en la medida en que el poder, una vez localizado, es posible hendirlo a través de resistencias individuales o colectivas que opten por una vida distinta, por una creación de sí inédita. Es, pues, en lo privado y en el reconocimiento en lo público de la libertad privada en dónde descansa el gradiente de la recepción política foucaultiana americana. Libertad sexual, reconocimiento público de tal libertad, y libertad para elegir el modo de vida privado de realización de sí. Sin duda, una aplicación práctica y política de la tarea foucaultiana que posee resultados altamente interesantes y valiosos pero que, considerada en su exclusividad, tiende a anular aquella política derivada de los análisis de Foucault

38 R. Rorty, «Entre liberalismo y filosofía. Entrevista con Rorty», op.cit., p. 1.

39 J. Sawicki, «Le féminisme et Foucault en Amérique du Nord : convergence, critique, possibilité», en D. Franche (ed.), Au risque de Foucault, Paris : Ed.Centre Pompidou, 1997, pp. 87-93. 
que puede poner en entredicho al liberalismo democrático. Finalmente, cabe un tercer elemento de reflexión acerca de esta recepción de la política foucaultiana. Se trata del texto, altamente aclamado en Estados Unidos, de James Miller, La passion Foucault ${ }^{40}$ demonizado en Francia por sus contenidos impropios de un intelectual, por la vinculación entre el pensamiento y la biografía pasional de Foucault. La intención de este texto es doble. Por un lado, proporcionar una explicación biográfica del pensamiento de Foucault a través de sus obsesiones, su sexualidad, su gusto por los límites, los excesos y la ausencia de moral. ${ }^{41}$ En definitiva, mostrar un Foucault maldito cuyo valor residiría en atreverse a recorrer lugares de gris moralidad. De este modo, Miller proporciona dos argumentos distintos para los dos rostros de Foucault que venimos tratando. El rostro americano - pesar de las querencias del propio Miller- participaría de esa búsqueda vital, y se correspondería con una suerte de intelectual maldito cuyo ejemplo de vida privada, de creación de sí, puede ser utilizado por los movimientos anteriormente citados, por una juventud americana sedienta de símbolos transgresores. Por otro lado, subrepticiamente, el libro de Miller es un ataque furibundo al nietzscheanismo del rostro francés de Foucault, llegando al extremo comparar su obra de inspiración nietzscheana con el Mein Kampf. ${ }^{42}$ Tales afirmaciones, no merecerían mayor atención si no fuera por el hecho de que el libro de Miller reunió a un buen número de intelectual liberales de izquierda en torno al seno de la revista The New Salmagundi Reader, dirigida por el propio Miller. Dicha revista se convirtió en una plataforma de descrédito del nietzscheanismo foucaltiano, considerado anarquista, peligroso e infame. ${ }^{43}$ Y, uno de los colaboradores de dicho movimiento, fue el mismo Rorty. Resulta enigmático el interés de Rorty por participar del descrédito basado en supuestas querencias sexuales y vitales hacia un pensador por él admirado. Podemos pensar que se trataba de un intento de desterrar a ese Foucault francés de Estados Unidos. De desterrar a la filosofía de la esfera pública. Sea como fuere, la colaboración de Rorty, llamada Paroxysms and politics, bascula entre la alabanza al libro de Miller, la crítica a la política nietzscheana de Foucault y una cierta duda acerca de los métodos empleados para ello. La tesis de Rorty se basa en la denuncia de que el objetivo político del Foucault nietzscheano no es la felicidad. Y ésta, la felicidad, ha sido el principal motivo político para la resistencia tanto al nazismo como al resto de políticas autoritarias. Bajo la renun-

40 J. Miller, La passion Foucault, Paris: Plon, 2004.

41 Ver al respecto, el artículo de R. Reid, «Foucault en Amérique», en Revue futur anterieur, 1994, pp. 23 y ss.

42 J. Miller, op. cit., p. 159.

43 Ver al respecto la caracterización del Foucault «americano» de J. Bouveresse, «L'objetivité, la connaissance et le pouvoir», en D. Eribon, L'infrequentable Michel Foucault, op.cit., pp. 134-135. 
cia a la felicidad como objetivo de la política, se esconde, para Rorty y Miller, el puro vacío: «Muchos intelectuales americanos izquierdistas todavía piensan que es posible extraer un nuevo tipo de política de Foucault, que apunte a alo más excitante que la felicidad. Pero el libro de Miller muestra claramente que Foucault no encontró nada mejor que sugerir» ${ }^{44} \mathrm{Y}$, para ejemplificar la vacuidad de la política foucaultiana, Rorty acude a uno de los lugares paradigmáticos de ejercicio político en el espacio foucaultiano: el GIP o Grupo de Información de Prisiones. La labor política ejercida en el GIP es, de nuevo, ridiculizada y condenada a participar de una suerte de vacío: «Los prisioneros necesitan tirar de la cadena en sus celdas mucho más de lo que alguien necesita la distinción entre el inocente consensuado sadomasoquista y el culpable no consensuado víctima de tortura». ${ }^{45}$ Sin embargo, el broche definitivo al nietzscheanismo político foucaltiano no se detiene en considerarlo como una vacuidad. Para Rorty, la política de Foucault, al no asumir la felicidad como objetivo social, al intentar no hacerse cómplice del poder, al cuestionar las estructuras mismas de la sociedad democrático liberal, no se queda en una opción por el simple vacío. Es una política basada en la muerte, en una vida-en-la-muerte referida a ir más allá de todos los límites, hasta el de la propia vida. ${ }^{46}$ Esta política de la muerte corresponde al uso del término «zombie» con el cual J.Miller adjetiva al mismo Foucault. Y, precisamente, esta denuncia del nietzscheanismo como voluntad de muerte, no sólo connota ecos de la utilización nacional-socialista de Nietzsche, sino que condena toda tarea política del Foucault francés. Una condena tanto política como ética. Pues una política que no posee la felicidad, sino la muerte en vida como objetivo pensable para la sociedad, es éticamente rechazable debido a que no respeta el principio de no crueldad, máxima del liberalismo rortyano. Así, el nietzscheanismo político de Foucault es desacreditado filosófica, política y éticamente como un disparate que no sólo pone en peligro a la sociedad entera, sino que no respeta los principios de comunidad y solidaridad que son los que garantizan la convivencia en una sociedad democrática como la que Rorty propone. Con ello, finalmente, Rorty puede afirmar que Foucault no contempla los beneficios de las comunidades liberales debido a que su política francesa le impide considerar la felicidad y la ausencia de crueldad como categorías dignas de ser tomadas en consideración:

Gran parte de la obra de Foucault consiste en la demostración del modo en que las pautas de enculturación características de las sociedades liberales han impuesto a sus miembros formas de coacción con las que sociedades anteriores, premodernas, 
no habían soñado. No está dispuesto, sin embargo, a admitir que estas coacciones se compensen con una disminución del dolor. ${ }^{47}$

Con ello, la crítica de Rorty se nos muestra como una crítica filosófica, política y ética a partir de la división entre los dos rostros foucaultianos que implican las lecturas francesa y norteamericana de su obra. Pese a que algunas de ellas, especialmente las políticas, sean de una dureza notable, no deja Rorty de considerar a Foucault como uno de los grandes filósofos últimos que «subrayó un nuevo conjunto de peligros para las sociedades democráticas». ${ }^{48}$ Quizás, para finalizar, cabría pensar con J. Bouveresse ${ }^{49}$ que estos peligros fueron señalados precisamente gracias a su alejamiento del consenso democrático y la euforia liberal, a su ironía pública, a su incombustible nietzscheanismo. Precisamente en estos peligros, marcados gracias al alejamiento de la euforia liberal, Foucault insistirá en su respuesta a Rorty. En una mesa redonda inédita, realizada en Berkeley en 1983, encontramos la única respuesta explícita a filosofía rortyana por parte de Foucault.

Ayer, cuando me preguntaron si estaba de acuerdo con lo que Rorty decía-cuando decía que todo está bien; que hay un juego en cierto momento, un juego de verdad y un juego político, y otro distinto en un momento diferente, y ambos son igualmente buenos-mi respuesta fue: para mí, nada está bien; todo es peligroso, pero no todo es igualmente peligroso. Y pienso que ésa es la tarea de los intelectuales: este trabajo intelectual no debe estar directamente relacionado con un tipo de gobierno o una estructura política, sino que debe ser, siempre, crítico hacia ellos desde el momento en que ya no podemos creer a alguien que supuestamente nos representa y gobierna. Es un interés negativo, sistemáticamente negativo. Y creo que es la única tarea política e intelectual que podemos realizar como intelectuales. ${ }^{50}$

En esta respuesta, se encofra todo el enfrentamiento entre las posiciones foucaultiana y rortyana. En primer lugar, se disuelve el rostro francés y americano del propio Foucault al introducir la sospecha nietzscheana en el seno de los ámbitos público y privado. Ya no es posible hablar de una versión americana de su labor, sino de problemas estratégicos en cada longitud y latitud, en cada geografía y tiempo. Su everything is dangerous se transforma en un not equally dangerous, ligando la tarea intelectual hacia la búsqueda del peligro

47 R. Rorty, Contingencia, ironía y solidaridad, op.cit, p. 82.

48 R. Rorty, Heidegger y otros pensadores contemporáneos, op. cit., p. 272.

49 J. Bouveresse, op. cit., p. 144.

50 Foucault, «Discussion with Michel Foucault, 21 April 1983», Berkeley, Archivo del IMEC, Côte D 250 (7), p. 1. 
concreto, del enemigo que está ligado a un campo, a un problema y a una geografía dada. Con ello, la división entre dos sentidos del poder queda diluida en una tarea ético-política primera que hace estallar los diques entre lo público y lo privado. La tarea filosófica no debe amparar por igual todo producto de la creación individual, sino sospechar qué juegos de poder públicos la han producido, cortocircuitándolos en clara línea nietzscheana. En segundo lugar, la respuesta de Foucault insiste en el hecho de que su tarea no se basa en la denuncia de ciertos excesos de la sociedad liberal, sino en detectar el mayor peligro estratégico como fruto de un activismo pesimista imbuido de sospecha hacia todo gobierno. A la hora de detectar un exceso, se debería marcar el margen de dominación aceptable y aceptado a partir del cual deviniese intolerable la actuación gubernamental. Sin embargo, desde una sospecha total, el establecimiento de este margen de dominación, de, en definitiva, una legitimidad de gobierno, se deshace como cómplice peligroso de la misma gobernación. Lo que nos lleva al tercer elemento que escenifica la ruptura total de las posiciones de ambos pensadores. La negatividad de la sospecha, la conciencia del peligro constante se traduce en una máxima ético-política de nunca aceptar un tipo de política. Más concretamente, se trata de alejar la tarea crítica y filosófica de toda relación con la estructura política de gobierno. En este sentido, la intervención política foucaultiana cobra el sentido de la crítica constante. Dicha intervención no puede identificarse con un gobierno de facto, pues, en ese caso, dejaría de ser crítica. Es, precisamente, el caso de Rorty. La intervención política rortyana, su tarea intelectual, consiste en transformar el sentido de dicha intervención política en la filosofía y acercarlo a la defensa de la política liberal. Al contrario, la intervención política foucaultiana, consiste en una negativa a adscribirse a algún tipo de política positiva. ${ }^{51}$ Debe siempre ser crítico hacia cualquier relación que pudiera establecerse entre la política efectiva y el pensamiento, pues, precisamente, el mayor peligro, el mayor enemigo de una ontología de nosotros mismos politizada a través de la experiencia de sí no es otro que los precipitados culturales producidos por la ecuación saber-poder. Si la tarea intelectual, para el Foucault americano sigue siendo, pese a su interés por el cuidado de sí, la preocupación por -e intento de anulación de- las construcciones que el entramado poder-saber realiza de la subjetividad, entonces, el rostro americano se disuelve en una tarea política por la resistencia, atravesada por la máxima de seguir persiguiendo al poder en su ejercicio. De hecho, para Foucault, ésta es

51 De ahí su negativa a considerar el nosotros rortyano como un elemento previo que implicaría una intervención política en la filosofía de corte liberal. En lugar de ello, el nosotros debería venir marcado por una práctica de resistencia, con lo cual no contaría implicación con ningún tipo de política positiva. Ver al respecto Foucault, Estética, Ética y Hermenéutica, Barcelona: Paidós, 1999, p. 356. 
la única tarea que puede realizarse como intelectual. Con todo ello, podemos afirmar que la filosofía de Foucault se rebela ante la lectura de Rorty, ante la posibilidad de su utilización como elemento del saber susceptible de mejorar la política liberal, que su posición se encona en el lugar de la crítica negativa, de la sospecha constante, de la genealogía. Frente a ello, la tarea filosófica de Rorty consiste en abrir esa intervención política en la filosofía desvinculándola de la resistencia y adaptándola a la política liberal, proponiendo para ello un tipo de intelectual y un tipo de ética basadas en la ironía y el sentimiento. Así pues, la fricción entre ambos pensadores se comienza a jugar en estos dos planos -el tipo de intelectual y el plano ético- convirtiéndose en una batalla por la filosofía, una oposición radical ante el intento de vincular la filosofía y la resistencia, por un lado, y la filosofía y el liberalismo, por otra. La primera, conduce a una sociedad en la cual la tarea del filósofo pasa por la sospecha, el hiper-activismo descorazonado, la esperanza sesgada por el desconsuelo de la teoría. El otro, el rortyano, nos lleva al ironismo, a una sociedad post-filosófica en la cual el pensamiento tendría, únicamente, el cometido de ayudarnos a crear nuestro yo privado y defenderlo. En el límite se tratan de dos opciones políticas antagónicas. Dos opciones que establecen su campo de batalla en la misma filosofía y que, abriéndola a la intervención política, la enfrentan a una dicotomía disyuntiva en la que se juega su sentido y su posibilidad: el poder o la resistencia, desarrollados en sus diferentes propuestas éticas y en sus diferentes modelos de intelectual. Con todo ello, la lectura que Rorty realiza de la obra de Foucault se puede leer como un intento de anular la capacidad política de resistencia de un pensamiento crítico que todavía cree que es posible seguir pensando sin desertar de la política. Así, entre Foucault y Rorty encontramos dos apuestas que marcan el presente de la filosofía política, que hacen de la filosofía el campo de un enfrentamiento político, el de la sumisión de la filosofía a la democracia o el de la crítica política como único modo de hacer filosofía. Ambos extremos coinciden en un punto esencial, que parece ser un elemento definitorio del presente: la necesidad de medirse con la política, la imposibilidad de pensar una filosofía ajena a los juegos de poder, a los juegos políticos, a la elección previa que determine su dirección. La necesidad, en fin, de establecer la opción metafilosófica y política que gobierna los mecanismos antaño impulsados por la contemplación.

\section{REFERENCIAS BIBLIOGRÁFICAS}

BOUVERESSE, J. 2001: «L'objetivité, la connaissance et le pouvoir», en D. Eribon (ed.), L'infrequentable Michel Foucault, Paris : EPEL, pp. 134-135. 
DESCOMBES, V. 1987: «Revision de Foucault: A critical reader», en London Review of Books, London, pp. 3-6.

EWALD, F. 1986: L'État providénce, Paris: Bernard Grasset.

FASSIN, E. 2001: «Résistances de Foucault», en D.Eribon (ed.), L'infréquentable Michel Foucault, Paris: EPEL, pp. 175-182.

FOUCAULT, M. 1983: «Discussion with Michel Foucault», 21 Abril 1983, Berkeley, Texto Inédito, Archivo del IMEC, Côte D 250 (7).

FOUCAULT, M. 1999: Estética, Ética y Hermenéutica, Barcelona: Paidós.

HALPERLIN, D. 2000: Saint Foucault, Paris: EPEL.

MILLER, J. 2004: La passion Foucault, Paris: Plon.

MACKE, F. J. 1995: «Pragmatism reconsidered», en L. Langsdorf (ed.), Recovering Pragmatism's Voice, New York: University of New York Press, pp. 162-178.

REID, R. 1994: «Foucault en Amérique», en Revue futur anterieur, Paris : L'Harmattan, pp. 22-28.

RORTY, R. Carta de Rorty a Foucault, 3 de Diciembre de 1980 y 28 Abril de 1981, Textos Inéditos, Archivo del Institut Mémoires de l'Edition Contemporaine (IMEC), Paris.

RORTY, R. 1981: «Beyond Nietzsche and Marx», London Review of Books, London, vol. 3, pp. 5-6.

RORTY, R. 1989: «Foucault et l'épistémologie», en D. Couzens(ed), Foucault: lectures critiques, Bruselas: DeBeck, pp. 55-64

RORTY, R. 1993: Heidegger y otros pensadores contemporáneos, Barcelona: Paidós.

RORTY, R. 1996: «Paroxysms and politics», en R. Boyers (ed.), The new Salmagundi Reader, Syracuse: Syracuse University Press, pp. 513-515.

RORTY, R. 1996: Contingencia, Ironía y Solidaridad, Barcelona: Paidós.

RORTY, R. 1996: Consecuencias del pragmatismo, Madrid: Tecnos.

RORTY, R. 2005: «Entre liberalismo y filosofía. Entrevista con Rorty», en Astrolabio. Revista electrónica de filosofía, $\mathrm{n}^{\circ} 0$, Barcelona.

SAWICKI, J. 1997: «Le féminisme et Foucault en Amérique du Nord: convergence, critique, possibilité», en D. Franche (ed.), Au risque de Foucault, Paris: Ed.Centre Pompidou, pp. 87-93.

JoAquín Fortanet FernándeZ es becario de Investigación doctoral de la Facultad de Filosofía de la Universidad de Barcelona. Asimismo, es miembro del Seminario de Filosofía Política de la misma facultad

\section{Publicaciones recientes:}

«Ciudadanía liberal y racionalidad de gobierno», en J. M. Bermudo (ed.), Hacia una ciudadanía de calidad, Ed. Horsori, Barcelona, 2007.

«Legitimidad, Poder y Orquídeas Silvestres», en J. M. Bermudo (ed.), Del humanismo al humanitarismo, Ed. Horsori, Barcelona, 2006. 
Línea de investigación:

La problemática de las relaciones entre la filosofía y la política a través de las obras de Michel Foucault y Richard Rorty.

Dirección postal:

C/Villarroel, 102, 3-1, 08011, Barcelona.

Dirección electrónica: joaquinfortanet@yahoo.es 